УДК 33.01

DOI: 10.14451/1.175.92

\title{
АНАЛИЗ ВОЗМОЖНЫХ ПУТЕЙ СНИЖЕНИЯ ЗАТРАТ В ОРГАНИЗАЦИИ
}

\author{
(C) 2019 Тахумова Оксана Викторовна \\ доцент кафедры экономического анализа
}

Кубанский государственный аграрный университет имени И.Т. Трубилина, Россия, Краснодар

(c) 2019 Горейко Надежда Игоревна

обучающийся 4-го курса экономического факультета

Кубанский государственный аграрный университет имени И.Т. Трубилина, Россия, Краснодар

(c) 2019 Петрова Елизавета Дмитриевна

обучающийся 4-го курса экономического факультета

Кубанский государственный аграрный университет имени И.Т. Трубилина, Россия, Краснодар

\section{(c) 2019 Чуев Сергей Сергеевич}

обучающийся 4-го курса экономического факультета

Кубанский государственный аграрный университет имени И.Т. Трубилина, Россия, Краснодар

Наиболее распространенными возможностями сокращения издержек в организации являются рациональное планирование продаж, переоценка номенклатуры товаров, использование незадействованных резервов, которые позволят повысить показатели эффективности производства. В статье рассматриваются пути сокращения затрат в организации, как классические, так и более современные. Раскрыты комплексные и индивидуальные подходы к обоснованию направлений снижения себестоимости. Выявлена наиболее оптимальная система управленческого учета для российских компаний, которая позволит сделать выводы о планировании и контроле будущих и настоящих затрат, а также поможет наиболее точно определить рентабельность товаров. Определены мероприятия по снижению затрат и исследованы проблемы по их реализации.

Ключевые слова: затраты, директ-костинг, стандарт-костинг, расходы, вэрибл-костинг, абзорпшен-костинг, учет.

Наиболее актуальный вопрос, который касается всех организаций, это экономия деятельности или же этому эквивалентное - сокращение расходов. Этот процесс необходим, так как, в большинстве случаев, получается, что сформированная себестоимость значительно сокращает уровень прибыли, на которую руководитель рассчитывал.

Навык экономичности крайне необходим предпринимателю, чтобы сделать свое дело рентабельным. Прибыль складывается из разницы доходов и расходов. Если предприниматель хочет иметь прибыльное дело, то ему необходимо: наращивать доходы и сокращать расходы [2]. K сожалению, на практике это сделать не так просто.

у каждой организации наступает период, когда топ-менеджеры осознают, что затраты завышены. Для того, чтобы производить какиелибо действия по себестоимости, первоначально необходимо классифицировать затраты по следующим категориям:
1) по уровню эффективности - это группа затрат, связанных с производством продукции (то есть на стадии создания товара организация будет нести убытки, а после его реализации будет в плюсе);

2) по значению релевантности - эта группа расходов, которые полностью зависят от управленческих решений;

3) по определению постоянства (то есть те затраты, на которые невозможно повлиять, так как они не зависят от производственного уровня организации);

4) по влиянию на себестоимость.

Исходя из этого, можно определить, что основную долю затрат организаций в России составляют затраты на производство, персонал и амортизацию (рисунок 1).

Наиболее распространенными возможностями сокращения издержек в организации являются: рациональное планирование продаж, переоценка номенклатуры товаров, использование незадействованных резервов, которые 

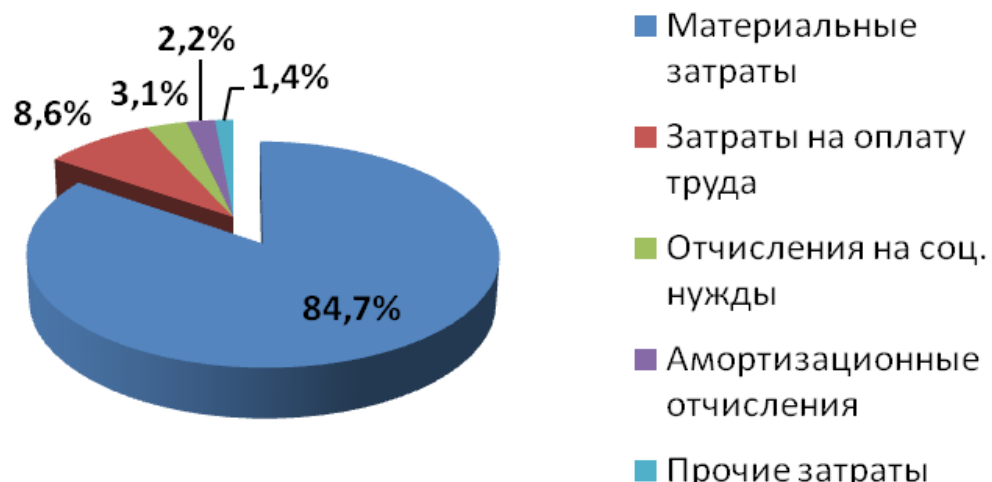

Puc. 1. Структура операционных расходов в 2017 году в организациях России,\% [18]

позволят повысить показатели эффективности производства. На современном этапе развития, организации стараются использовать не просто традиционные методы сокращения расходов, а наиболее комплексные и индивидуальные подходы. Ниже рассмотрены несколько способов, которые помогут фирме сэкономить средства.

Один из способов снижения затрат на производстве: это правильная логистика склада и транспорта. Если рассматривать совершенствование склада, то именно там возможность сократить издержки за счет устаревшего оборудования. Именно оно не позволяет сырью соответствовать необходимым требованиям. Если на складе заменят оборудование, то это позволит не только снизить производственные затраты, но и позволит эффективно работать с поставщиками.

Другим способом сокращения затрат является поиск новых партнеров. В большинстве случаев компании сотрудничают с небольшими индивидуальными предпринимателями, у которых можно приобрести канцелярские товары для офиса. Что же касается более крупных закупок, то можно искать других партнеров, с которыми можно заказывать что-то вместе. Тем самым, получая скидку или разделив стоимость доставки.

Также, наладив взаимодействие между отделом закупок и производственным сектором, будет возможность снизить затраты. Взаимная поддержка этих подразделений позволит выбрать нужно поставщика, который будет поставлять сырье, соответствующего качества, цены и объема.

На данном этапе развития экономической науки наиболее распространенными методами снижения затрат в организации являются «стан- дарт-костинг» и «директ-костинг». Эти методы имеют как сходства, так и различия, но им нашли применение, как на Западе, так и в реалиях российской экономики.

Еще один метод сокращения затрат в организации: снижение переменных затрат, размер которых зависит от масштабов производства. Чем больше увеличиваются масштабы с каждым месяцем, тем больше растут переменные затраты. Этот метод имеет название «директ-костинг» - это теория управленческого учета, суть которой заключается в делении затрат на постоянные и переменные.

Система директ-костинга относится к системам учета усеченных затрат. Она является традиционной системой управленческого учета. Впервые сам термин «директ-костинг» был введен американским ученым Джонатаном Харрисом в 1936 году. Из буквального перевода директ-костинга можно сделать вывод, что Харрис под директ-костингом понимал систему учета усеченной себестоимости только по прямым затратам, то есть в себестоимость конкретного вида изделия включались прямые затраты. В свою очередь, прямые затраты - это те затраты, которые возможно соотнести с конкретным видом изделия. Естественно, он не был первооткрывателем в рамках формирования усеченной себестоимости, то есть он развивал идеи, которые предлагались его предшественниками, но в любом случае, можно сказать, что он является основателем системы директ-костинга. В российской практике учета на протяжении длительного периода времени, если рассматривать советский этап развития нашей экономики, калькулировали себестоимость полную, то есть включали в себестоимость конкретного вида изделия абсолютно все затраты. На западе ситуа- 
ция обстояла иначе, там уже относительно давно пришли к выводу, что система калькулирования полной себестоимости, ее называют еще абзорпшен-костинг, не является эффективной и не соответствует современным информационным потребностям экономических субъектов. В России ситуация в последнее время стала складываться аналогичным образом, большинство наших экономистов тоже пришли к выводу, что все-таки для принятия эффективных управленческих решений, в случае если внедряется управленческий учет в организацию, все же целесообразно сформировать усеченную себестоимость, то есть использовать систему директ-костинга. Однако очень часто в различных источниках встречаются различные подходы к определению системы директ-костинга. И вот как раз отсутствие этого терминологического единства зачастую препятствует экономическим субъектам в принятии эффективных экономических решений, мешает специалистам общаться между собой в связи с тем, что иногда под одним и тем же словом разные специалисты понимают разные понятия. В связи с этим на сегодняшний момент система директ-костинга предполагает под собой три базовых подхода.

Первое: классический директ-костинг. Он является наиболее простым способом расчета усеченной себестоимости. В основе классического директ-костинга лежит такой принцип: себестоимость конкретного вида изделия включает только прямые затраты, а все остальные затраты, которые возникают в процессе осуществления финансово-хозяйственной деятельности, являются косвенными и относятся к расходам периода, то есть списывают на финансовые результаты. Таким образом, классический директ-костинг предполагает, что усеченная себестоимость формируется только по прямым затратам. Сразу необходимо отметить, что данный способ формирования усеченной себестоимости является самым достоверным и нетрудоемким, поскольку нет необходимости распределять какие-либо косвенные расходы. И опять же, когда мы распределяем косвенные расходы, мы самостоятельно определяем какую-либо базу распределения и возможно какие-то субъективные ошибки в результате распределения. Так, классический директ-костинг не искажает себестоимость путем распределения косвенных расходов.

Ученые выяснили, что прямые затраты - это не единственные расходы, которые могут возникать в процессе производственной деятель- ности. И соответственно, возникает следующая разновидность системы учета усеченной себестоимости, то есть системы директ-костинга, которая предполагает, что в эту усеченную себестоимость включаются все производственные затраты. И при этом под производственными расходами понимаются не только прямые, но и косвенные.

Так, второй подход в системе директ-костинга предполагает, что мы в усеченную себестоимость будем включать прямые и косвенные производственные расходы. Недостатками этого способа состоят в том, что производственные косвенные расходы все-таки нужно распределять между конкретными видами изделия, то есть будет искажаться себестоимость путем осуществления баз распределения. Кроме того, в производственных расходах, которые являются косвенными. В любом случае, существует часть каких-то постоянных расходов, которые с производством не связаны.

Итак, третья система директ-костинга: вэрибл-костинг. Этот подход является наиболее прогрессивным в современных экономических условиях, то есть способствует принятию эффективных управленческих решений. Этот подход предполагает, что в себестоимость конкретного вида изделия включаются прямые затраты, то есть которые могут быть соотнесены с конкретным видом изделия, и переменная часть косвенных затрат, то есть части общепроизводственных расходов. Таким образом, в усеченную себестоимость включаются не только прямые затраты, но и переменная часть общепроизводственных расходов, которая является по своей сути косвенной.

В России эти методы только ищут свое место, в то время, как западные менеджеры во всю используют эти методы для снижения затрат в организации (таблица 1).

Для того, чтобы в российские организации возможно было внедрить один из предложенных методов снижения затрат необходимо дать оценку:

- финансовым возможностям организации;

- внешней политике организации;

- форме собственности;

- целям и задачам организации;

- степени технического оснащения;

- виду налогооблагаемой базы;

- компетентности коллектива;

• общей стратегии организации. 
Таблица 1. Доля методов, применяемых для сокращения издержек в других странах [1]

\begin{tabular}{|l|c|c|c|}
\hline \multicolumn{1}{|c|}{ Страна } & Метод «директ-костинг» & $\begin{array}{c}\text { Метод «стандарт- } \\
\text { костинг» }\end{array}$ & Другие методы \\
\hline США & $31 \%$ & $65 \%$ & - \\
\hline Канада & $48 \%$ & $52 \%$ & $67 \%$ \\
\hline Австралия & $33 \%$ & & $69 \%$ \\
\hline Япония & $31 \%$ & \\
\hline Швеция & $42 \%$ & & $58 \%$ \\
\hline Великобритания & $52 \%$ & $48 \%$ \\
\hline
\end{tabular}

Исходя из общего положения и опираясь на совокупность всех ранее вышеперечисленных и упомянутых фактов, можно сделать вывод, какая система управленческого учета больше подойдет организации. Система, которая помимо того, что будет включать в себя данные о пересчете и калькулировании издержек, еще и позволит сделать выводы о планировании и контроле будущих и настоящих затрат, а также сможет высчитать рентабельность товаров.

На сегодняшний день производственные российские организации сталкиваются с проблемой внедрения учета издержек, так как существуют пробелы в симбиозе между финансовой и производственной бухгалтерии.

Но, исключая все трудности внедрения, у любого метода снижения затрат существует ряд преимуществ:

- объяснения завышенной себестоимости;

- свободное изучение информации;

- построение эластичного ценообразования;

- анализ рентабельности продаж и продукции;

- определение финансового рычага и точки безубыточности;

- после учета всех затрат есть возможность построения плана продаж.
Однако, вместе со значимыми аргументами в пользу методов снижения затрат, существуют и ряд отрицательных аспектов:

1) проблема классификации затрат, не все организации могут запросто отнести те или иные издержки к определенному виду затрат;

2) исследование внешней среды;

3) поиск информации о размере полной себестоимости.

Рассмотрев значительное количество методов сокращения издержек, необходимо сделать вывод о том, что каждый вариант принесет свои положительные тенденции в развитие организации. Эти способы являются эффективными аппаратом управления издержками, как в условиях стабильной экономической ситуации, так и в кризисном положении. Все методы видоизменяются под деятельность организации, то есть они не привязаны к определенной отраслевой сфере. Основным плюсом применения таких методов в организации является то, что они, управляя затратами, эффективно влияют на финансовые возможности организации. Оптимизация затрат открывает возможности для создания конкурентных преимуществ организации: позволяет добиться более низкой цены на товары и услуги через снижение себестоимости.

\section{Библиографический список}

1. Басовский Л.Е., Басовская Е.Н. Комплексный экономический анализ хозяйственной деятельности.-М.: ИНФРА-М, 2015-366 с.

2. Борисов А.Б. Большой экономический словарь.- Отдельное издание.- М.: Книжный мир, 2010. - 864 с.

3. Анализ финансового состояния предприятия [Электронный ресурс].- Режим доступа: http://www.grandars. ru/college/ekonomika-firmy/finansovyy-analiz-predpriyatiya.html, свободный. - (дата обращения: 20.03.2019).

4. Гоник, Г.Г. Экономико-статистический анализ влияния наличия и использования основных производственных фондов на эффективность производства / Г.Г. Гоник, А.А. Якушкина // В сборнике: Наука сегодня: теория, практика, инновации. Сборник ХІ Международной научно-практической конференции. 2017. С. $237-243$.

5. Иматаева А.Е. Экономический анализ [Электронный ресурс]: учебное пособие для студентов специальности «учет и аудит»/ А.Е. Иматаева - Электрон. текстовые данные.-Алматы: Альманах, 2016. - 117 с. - Режим доступа: http://www.iprbookshop.ru/69250.html.- ЭБС «IPRbooks». 